\title{
Long-Term Potentiation in an Avian Basal Ganglia Nucleus Essential for Vocal Learning
}

\author{
Long Ding ${ }^{1}$ and David J. Perkel ${ }^{2}$ \\ 'Department of Neuroscience, University of Pennsylvania, Philadelphia, Pennsylvania 19104, and 2Departments of Biology and Otolaryngology, University \\ of Washington, Seattle, Washington 98195-6515
}

\begin{abstract}
Vocal learning in songbirds provides an excellent model for sensorimotor learning in vertebrates, with an accessible, well-defined behavior and discrete neural substrate. The rich behavioral plasticity exhibited by songbirds, however, contrasts starkly with the scarcity of candidate cellular mechanisms. Here, we report for the first time on an activity-dependent form of synaptic plasticity in area X, a component of the song system required for song learning and song maintenance. In slice preparations of zebra finch area X, pairing of high-frequency presynaptic stimulation with postsynaptic depolarization induces Hebbian long-term potentiation (LTP) of the glutamatergic inputs to spiny neurons. This form of LTP requires activation of NMDA receptors and D1-like dopamine receptors. In addition, LTP is observed in birds as young as $47 \mathrm{~d}$ after hatching and also in adult birds but not in younger birds, providing evidence of developmental regulation of the onset of synaptic plasticity. These properties make this form of LTP the best known candidate mechanism for reinforcement-based vocal learning in juveniles and song maintenance in adult birds.
\end{abstract}

Key words: synaptic plasticity; song learning; songbird; basal ganglia; dopamine; glutamate

\section{Introduction}

Vocal learning in songbirds has been an excellent vertebrate model of motor learning because of its easily measurable behavior and discrete neural substrate. A young zebra finch goes through two general phases during song development (Immelmann, 1969). In the sensory learning phase (20-60 d after hatching), a young male memorizes a tutor song, usually from his father. In the sensorimotor learning phase (35-90 d after hatching), the young bird practices refining his own vocalizations to match the memorized template, after which he produces a highly stereotyped song resembling the tutor song. After the learning phases, the bird actively maintains song quality using auditory feedback (Nordeen and Nordeen, 1992; Woolley and Rubel, 1997; Leonardo and Konishi, 1999; Brainard and Doupe, 2000b; Lombardino and Nottebohm, 2000). The brain regions underlying vocal learning and production are known as the song system (Fig. 1A) (Nottebohm et al., 1976). In particular, the anterior forebrain pathway (AFP) is essential for song learning in juveniles and song maintenance in adult birds, but this region is not required for song production (Bottjer et al., 1984; Sohrabji et al., 1990; Scharff and Nottebohm, 1991; Williams and Mehta, 1999; Brainard and Doupe, 2000a). Detailed neural mechanisms medi-

Received Sept. 24, 2003; revised Nov. 14, 2003; accepted Nov. 15, 2003.

This work was supported by grants to D.J.P. from the National Institutes of Health (NIH) (R01-MH56646 and R01-MH0066128) and the National Science Foundation (IBN0196104) and by NIH-National Institute on Deafness and Other Communication Disorders P30 Core Grant DC04661. D.J.P. is an affiliate of the Virginia Merrill Bloedel Hearing Research Center. We thank Julie Kauer and Michele Solis for helpful discussions and valuable comments on this manuscript.

Correspondence should be addressed to Dr. Long Ding, Laboratory of Sensorimotor Research, National Eye Institute, National Institutes of Health, Building 49, Room 2A50, Bethesda, MD 20892. E-mail: ding|@nei.nih.gov.

DOI:10.1523/JNEUROSCI.4358-03.2004

Copyright $\odot 2004$ Society for Neuroscience $\quad$ 0270-6474/04/240488-07\$15.00/0 ating the behavioral plasticity are currently under extensive study but have not been identified.

As in other systems, long-lasting activity-dependent changes in synaptic strength are generally thought to play a critical role. Two types of long-term synaptic plasticity have been demonstrated in the song system, at separate glutamatergic synapses in the lateral magnocellular nucleus of the anterior nidopallium (LMAN) (Boettiger and Doupe, 2001; Reiner et al., 2004). However, both types of plasticity are restricted temporally to the sensory learning phase, making them unlikely primary candidates for mediating sensorimotor learning in juveniles, or for song maintenance and plasticity in adult birds.

Here, we report activity-dependent plasticity at synapses in area $\mathrm{X}$, a region required for song learning and maintenance. In slice preparations of zebra finch area $X$, pairing of high-frequency presynaptic stimulation with postsynaptic depolarization can potentiate glutamatergic projections from HVC [used as the proper name (Reiner et al., 2004)] and LMAN to spiny neurons in area X. This form of long-term potentiation (LTP) is activity dependent and synapse specific; it also requires activation of NMDA receptors and D1-like dopamine (DA) receptors; it is observed in adult and older juvenile birds but not in birds younger than $37 \mathrm{~d}$ old. Thus, for the first time, we have identified a form of LTP that could underlie sensorimotor learning and song maintenance by enhancing specific inputs from HVC/LMAN to area X.

\section{Materials and Methods}

Brain slices from male zebra finches were obtained as described previously (Ding and Perkel, 2002). Whole-cell recordings were made in the presence of $150 \mu \mathrm{m}$ picrotoxin (Sigma, St. Louis, MO) in artificial CSF containing (in mM) $119 \mathrm{NaCl}, 2.5 \mathrm{KCl}, 1.3 \mathrm{MgSO}_{4}, 2.5 \mathrm{CaCl}_{2}, 1$ $\mathrm{NaH}_{2} \mathrm{PO}_{4}, 26.2 \mathrm{NaHCO}_{3}$, and $11 \mathrm{D}$-glucose. For recordings in voltageclamp mode, pipettes were filled with internal solution containing (in mM) 120 Cs-gluconate, 10 HEPES, 0.2 EGTA, 8 NaCl, 2 ATP, 0.3 GTP, 2 

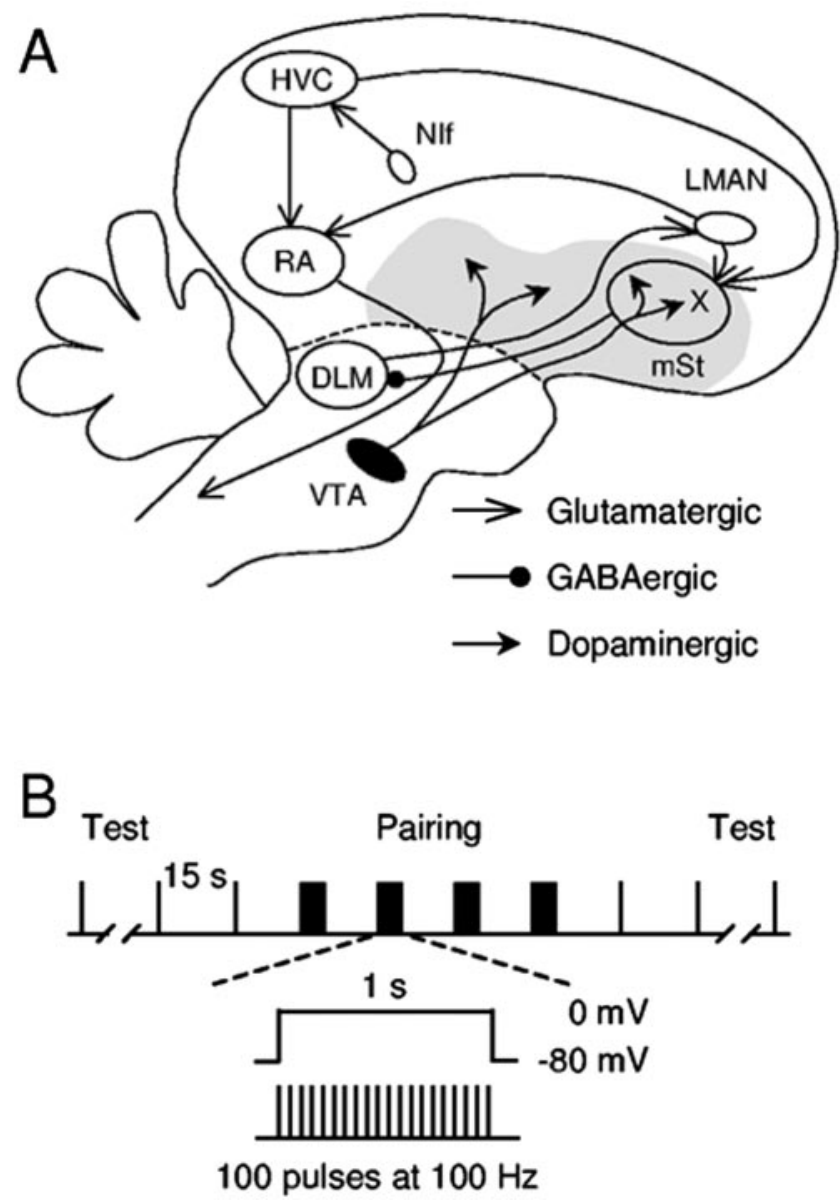

Figure 1. The song system and the pairing protocol used. $A, A$ simplified diagram of the oscine song system. The song system consists of three major pathways. The interfacial nucleus of the nidopallium (NIf) likely provides key auditory input to the song system. The motor pathway consists of nucleus HVC (used as a proper name) and the robust nucleus of arcopallium (RA). See Reiner et al. (2004) for revised avian brain nomenclature. The AFP starts with the projection from HVC to area X, a part of the avian basal ganglia surrounded by the medial striatum (mSt). Area $X$ receives glutamatergic inputs from HVC and LMAN. It also receives dense dopaminergic inputs from the VTA. DLM, Medial portion of the dorsal lateral nucleus of the anterior thalamus. The gray area represents the basal ganglia (paleostriatal complex). $B$, Illustration of the pairing protocol used to induce synaptic plasticity.

$\mathrm{MgCl}_{2}, 5$ QX-314, 10 phosphocreatine, and 10-17 biocytin, $\mathrm{pH} 7.25-$ 7.35. In some experiments, $20 \mathrm{~mm}$ BAPTA (Sigma) and $80 \mathrm{~mm}$ Csgluconate were used, while omitting EGTA. For recordings in currentclamp configuration, Cs-gluconate was replaced with K-methylsulfate, and QX-314 was omitted from the internal solution. Spiny neurons were identified using established criteria (Farries and Perkel, 2002; Ding et al., 2003). EPSCs or EPSPs were evoked by electrical stimulation of the HVC/ LMAN afferents with bipolar stainless steel electrodes. Stimulating electrodes were always placed in area $\mathrm{X}$ dorsal to the recorded neuron, but their relative position in other axes varied. Putative monosynaptic EPSCs were identified by their short and stable latency and, in some cases, by their ability to follow high-frequency stimulus trains up to $50 \mathrm{~Hz}$. The stimulus strength was adjusted to minimize failures and polysynaptic events. Baseline EPSC/EPSPs were evoked at intervals of $15 \mathrm{sec}$. The pairing protocol in experiments in voltage-clamp mode is shown in Figure $1 \mathrm{~B}$. In experiments in current-clamp mode, postsynaptic depolarization to $0 \mathrm{mV}$ was substituted with suprathreshold current injection. Input resistance and series resistance were monitored throughout each experiment. For experiments in voltage-clamp mode, cells were excluded from analysis if there was a $>20 \%$ change in series resistance or if the input resistance to series resistance ratio was lower than 10. For experiments in current-clamp mode, cells were excluded if input resistance increased by
$>20 \%$. Paired-pulse stimuli at $50 \mathrm{msec}$ intervals were delivered to test for possible involvement of presynaptic sites of action. Drugs were applied in the bath and included $(\mathrm{R})(+)-\mathrm{SCH}-23390$ hydrochloride (Sigma), sulpiride, and D(-)-2-amino-5-phosphonopentanoic acid (D-APV) (Tocris, Ellisville, MO).

EPSC size was measured as the peak amplitude of the evoked synaptic current. To monitor changes in EPSP size, the initial slope of the EPSP was estimated by linear regression in the $10-90 \%$ rise phase of the EPSP. EPSC sizes or EPSP slopes measured from 10 iterations before and 8-20 min after pairing, depending on the length of stable recordings, were used for statistical analysis. The paired-pulse ratio (PPR) and coefficient of variation (CV) in EPSC size were calculated using the same 10 iterations as described for each condition. Statistical results were obtained with internal functions in Prism 3.0 (Graph Pad Software Inc., San Diego, CA). The two-tailed Wilcoxon signed rank test was used for paired comparisons. The two-tailed MannWhitney $U$ test was used for unpaired comparisons. Dunn's multiple comparison test was used for comparisons among groups.

\section{Results}

\section{Concurrent presynaptic tetanic stimulation and postsynaptic} depolarization induce LTP

We recorded from spiny neurons in slices of area X from adult zebra finches. In adulthood, zebra finches actively maintain their song quality and stereotypy using the AFP, likely by associating neural activity related to vocal output and auditory feedback. In several brain areas, activity-dependent or associative LTP requires both the release of glutamate and depolarization of the postsynaptic neuron. We, therefore, paired $100 \mathrm{~Hz}$ electrical stimulation (tetanus) with simultaneous postsynaptic depolarization to $0 \mathrm{mV}$ in zebra finch slices containing area $\mathrm{X}$ (Fig. $1 B$ ). We observed long-lasting potentiation of the EPSC after pairing (Fig. 2). In Figure 2, $A$ and $B$, a potentiation of $\sim 60 \%$ developed within $8 \mathrm{~min}$ after pairing and lasted until the end of the recording (i.e., $22 \mathrm{~min}$ after the pairing). There was no change in the series or input resistance. We tested the same pairing protocol on a total of 11 cells from 11 birds, and the average response showed a significant potentiation of $37 \%$ (Fig. $2 C)(p=0.002)$. In seven of these cells, pairing induced significant potentiation of the EPSC with an average magnitude of $46 \%$ and a range from 13 to $79 \%$. EPSC size was not significantly changed in four other cells.

\section{LTP induction is Hebbian}

We next performed experiments to test the requirement for presynaptic activity and postsynaptic depolarization for LTP induction. To test whether presynaptic activity is necessary for LTP induction (i.e., whether the depolarization alone could induce LTP), we stimulated two independent sites within area $\mathrm{X}$ in eight experiments. During a postsynaptic depolarization to $0 \mathrm{mV}$ in these experiments, one site was tetanized, whereas the other was not stimulated. EPSC potentiation developed in the tetanized pathways in five cells, whereas the nonstimulated pathways were either significantly depressed $(n=3)$ or not affected $(n=2)$. An example of the latter is shown in Figure $3 A$, in which pathway 1 underwent pairing and pathway 2 was not stimulated during the depolarization. After the pairing, EPSC size increased by almost $80 \%$ in pathway 1 , whereas there was no change in EPSC size in pathway 2. In the remaining three cells, the tetanized pathway failed to develop potentiation; in one of those cells, significant depression was observed in the nonstimulated pathway. Overall, regardless of the changes in the tetanized pathway, the nonstimulated pathway was depressed by an average of 20\% (range, 10-29; $p=0.0156$ ) (Fig. 3C,D). This result is significantly different from the effect of pairing the depolarization with tetanus $(p<0.001)$. Thus, depolarization to $0 \mathrm{mV}$ alone is not sufficient to induce LTP. 
Synaptic activity is necessary for the potentiation (i.e., the pairing-induced potentiation is synapse specific).

We next tested whether $100 \mathrm{~Hz}$ tetanic stimulation alone at a holding potential of $-80 \mathrm{mV}$ was sufficient for LTP induction. A representative experiment is shown in Figure $3 B$, in which $100 \mathrm{~Hz}$ tetanus alone had no effect on the EPSC size ( $p=$ $0.6305)$. No potentiation was observed after tetanus alone in the nine cells that underwent only the tetanus. Significant depression developed in two cells (by 19 and $33 \%$, respectively), whereas there was no change in the EPSC size in the others. Overall, tetanus alone induced no significant change in the EPSC size $(p=0.1641)$. Tetanus-induced change in the EPSC size averaged $-6 \%$ and ranged from -33 to $26 \%$, significantly different from the effect of pairing tetanus with depolarization (Fig. $3 C, D)(p<0.05)$. These results indicate that tetanus alone is not sufficient for the induction of potentiation. To explore whether a strong depolarization is necessary, we paired tetanus with a weaker depolarization to $-40 \mathrm{mV}$. In four cells tested, this modified pairing protocol also induced significant LTP in two cells by 82 and $36 \%$, respectively (data not shown), suggesting that if paired with tetanus, a depolarization to $-40 \mathrm{mV}$ or above is sufficient for LTP induction. Taken together, these results demonstrate that concurrent presynaptic activation and postsynaptic depolarization are required for LTP induction (i.e., the LTP induction is Hebbian).

To test whether LTP can be induced in more physiological conditions, we also made whole-cell recordings from spiny neurons using $\mathrm{K}^{+}$-based internal solutions in the current-clamp mode. Pairing of $100 \mathrm{~Hz}$ electrical stimulation with suprathreshold current injection potentiated the EPSP slope by $13-333 \%$ ( $n=4$ of 7 ; data not shown). In all cells, pairing did not induce bursting of action potentials, likely because of the delayed firing properties of spiny neurons. The pairing of $20 \mathrm{~Hz}$ electrical stimulation potentiated the EPSP slope by 23 and $67 \%(n=2$ of 3 ; data not shown), indicating that presynaptic activity of frequency as low as $20 \mathrm{~Hz}$ is also effective for LTP induction. These results suggest that LTP is inducible in area X under physiological conditions.

\section{LTP induction requires activation of NMDA and D1-like DA receptors}

The requirement of concurrent presynaptic and postsynaptic activities resembles that for the LTP induction at the glutamatergic synapses of the Schaffer collateral-commissural pathway in the mammalian hippocampus (Nicoll et al., 1988), which depends on
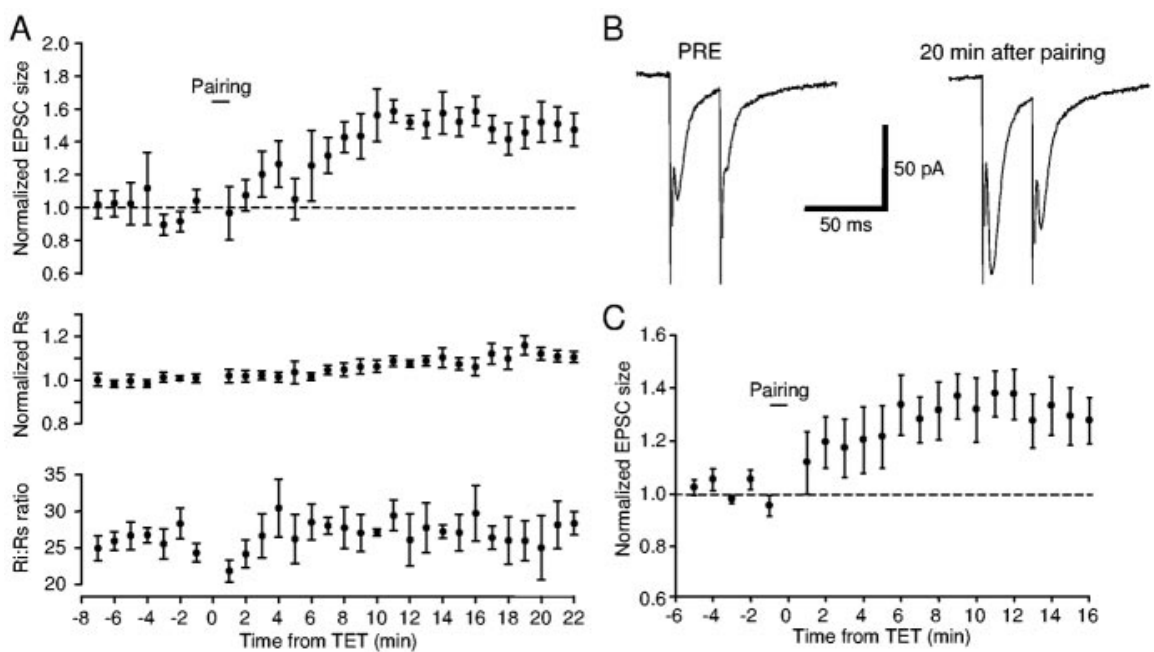

Figure 2. Pairing of tetanic presynaptic stimulation and postsynaptic depolarization induced LTP of the EPSC. A, EPSC size was increased by $\sim 60 \%$ after pairing in a spiny neuron in area X. Each data point is a 1 min average ( 4 raw traces). Error bars indicate SD. Top, Normalized EPSC size as a function of time; middle, normalized series resistance; bottom, ratio of input resistance to series resistance. $B$, Example traces taken immediately before and $20 \mathrm{~min}$ after pairing. Each trace is an average of five consecutive raw traces. The holding potential was $-80 \mathrm{mV}$. C, Average normalized EPSC from 11 cells tested $(n=10$ for data points 13-15 min after pairing; $n=9$ for data point 16 min after pairing). Error bars indicate SE.
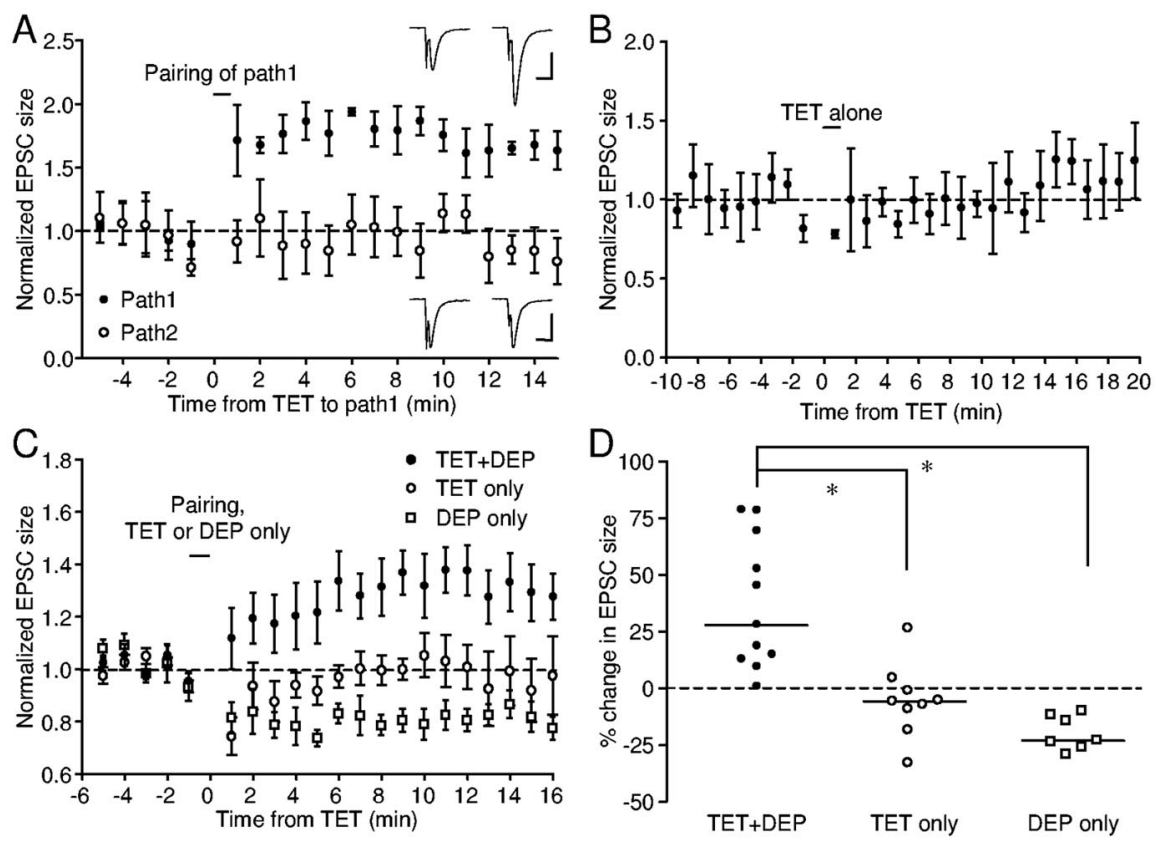

Figure 3. LTP induction requires concurrent presynaptic activity and postsynaptic depolarization. $A$, In a spiny neuron in area $X$, two independent pathways were stimulated. Pathway 1 underwent the pairing protocol, whereas pathway 2 was not stimulated during the depolarization. Pairing induced potentiation of pathway 1, while leaving pathway 2 unchanged. Each data point is a $1 \mathrm{~min}$ average of normalized EPSC values. Error bars indicate SD. Insets, Example traces. Calibration: $10 \mathrm{msec}$; top, 100 pA; bottom, 50 pA. $B$, In this spiny neuron, tetanizing one pathway without simultaneous postsynaptic depolarization did not change EPSC size. C, Average time course of normalized EPSC size for three protocols: pairing (TET+DEP), tetanus alone (TET only), and postsynaptic depolarization alone (DEP only). D, Summary of percentage change in EPSC size for the above three protocols. The dashed line indicates zero percent, and the horizontal lines indicate median values. ${ }^{*} p<0.05$, Dunn's multiple comparison test. 

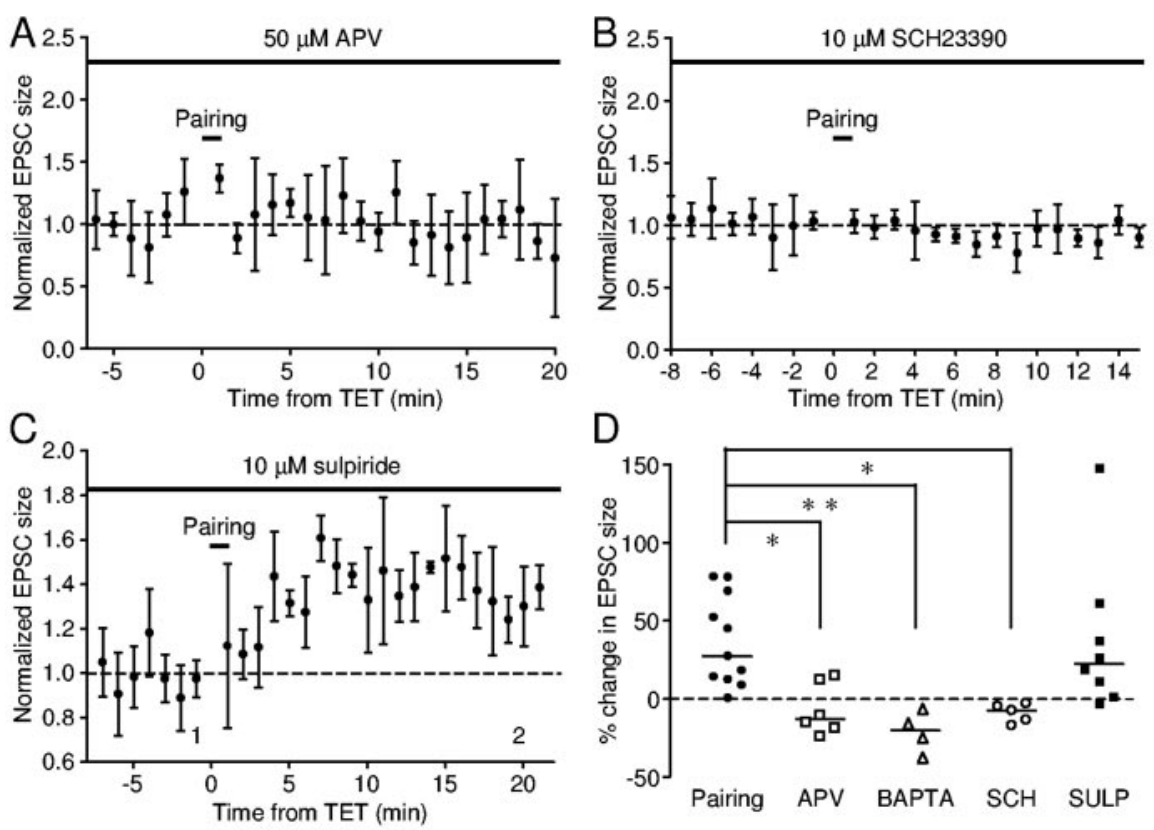

Figure 4. LTP induction requires activation of NMDA receptors and D1-like DA receptors. $A$, Incubation in APV ( $50 \mu \mathrm{m})$ blocked pairing-induced LTP in this neuron. $B$, In the presence of $S C H-23390(10 \mu \mathrm{m})$, pairing failed to induce LTP in this neuron. C, Normal LTP was induced in the presence of sulpiride $(10 \mu \mathrm{M})$ in this neuron. D, Summary of percentage change in EPSC size for the above three conditions. The dashed line indicates zero percent, and the horizontal lines indicate median values. ${ }^{*} p<0.05$ and ${ }^{* *} p<$ 0.01 , Dunn's multiple comparison test.

NMDA receptor antagonist, pairing failed to induce LTP in all six cells tested (Fig. 4A,D) $(p=1)$. A significant depression in the EPSC $(23 \%)$ was seen after pairing in one cell. These changes are significantly different from those induced in the absence of APV $(p<$ 0.05). Thus, the pairing-induced LTP is dependent on activation of NMDA receptors.

NMDA receptors permit calcium entry, facilitating Hebbian LTP in hippocampal neurons. We found that inclusion of $20 \mathrm{~mm}$ BAPTA in the recording pipette completely blocked LTP induction at area $\mathrm{X}$ synapses (Fig. $4 D)(n=4 ; p<0.01)$. These data indicate that a rise in intracellular calcium levels is also essential for LTP induction.

Because area $\mathrm{X}$ receives rich dopaminergic innervation from the ventral tegmental area (VTA), tetanic stimulation within area $\mathrm{X}$ likely induces DA release in addition to glutamate release. We next tested whether DA is required for LTP induction. In all five cells tested, pairing failed to induce LTP in the presence of $10 \mu \mathrm{M}$ SCH-23390, a D1-like DA receptor antagonist (Fig. $4 B, D$ ). This is significantly different from the effects of pairing in the absence of SCH-23390 $(p<0.05)$. In contrast, in the presence of $10 \mu \mathrm{M}$ sulpiride, a D2-like DA receptor antagonist, pairing induced LTP in five of eight cells tested (Fig. 4C,D). There was no significant difference between changes induced in the presence and absence of sulpiride $(p>0.05)$. Thus, the pairing-induced LTP requires activation of D1-like DA receptors but not D2-like DA receptors.

\section{LTP expression is not associated with changes in PPR or CV}

As an initial step toward determining the mechanisms underlying the expression of pairing-induced LTP, we compared the PPR and the CV of EPSCs before and after LTP induction, because these are two useful indicators of presynaptic release probability (del Castillo and Katz, 1954; Malinow and Tsien, 1990; Manabe et al., 1993). In the example shown in Figure $5 A$, there was no change in the PPR in either pathway ( $p=0.1132$ and 0.7394 , respectively), although pathway 1 was significantly potentiated after pairing (Fig. 3A). We delivered paired stimuli in 10 cells that underwent the pairing protocol and found no significant change in the PPR, either as a whole or after excluding cells that did not develop potentiation after pairing (Fig. $5 B)(p=0.7695$ and 1 , respectively $)$. We also found no significant change in the $\mathrm{CV}$, either as a group or after excluding cells that did not develop potentiation (Fig. $5 C$ ) ( $p=0.2783$ and 0.375 , respectively). These data show that the pairing-induced potentiation of EPSC is not associated with changes in the PPR or CV, consistent with the idea that the potentiation is mediated by postsynaptic mechanisms.

\section{LTP is present in juvenile birds}

Synaptic plasticity, such as LTP, has been a prominent cellular candidate for mediating behavioral plasticity. Pairing-induced potentiation in male adult zebra finches provides a possible mechanism underlying active song maintenance in adult songbirds and could also contribute to song degradation known to occur after manipulation of the auditory feedback (Woolley and Rubel, 1997; Leonardo and Konishi, 1999; Lombardino and Nottebohm, 2000; Brainard and Doupe, 2001) or tracheosyringeal nerve injury (Williams and Mehta, 1999). We next tested whether this form of LTP is also present in young zebra finches undergoing song learning. Indeed, we were able to induce LTP with the same pairing protocol in slices obtained from male juvenile birds as young as $47 \mathrm{~d}$ after hatching (Fig. 6A, B). However, in seven neurons from three birds between 24 and $37 \mathrm{~d}$ old, the same LTP induction protocol failed to induce LTP; six of these birds showed significant depression instead (Fig. 6B). In eight birds between 47 and $75 \mathrm{~d}$ old, LTP was induced in about half of the cells (Fig. $6 B)(n=7$ of 15) and significant depression was induced in one. The likelihood of LTP induction was significantly lower in birds $24-37 \mathrm{~d}$ old than in other age groups ( $\chi^{2}$ test; $p=$ 0.0261 ), whereas no significant difference was observed between the $47-75 \mathrm{~d}$ age group and adult birds ( $\chi^{2}$ test; $p=0.6923$ ). Although the largest potentiation tended to occur in juvenile birds, there was no significant difference in our samples between juvenile and adult birds ( $p=0.1282)$. As in adult birds, potentiation of EPSC size in younger birds ( $<75 \mathrm{~d}$ old) was not accompanied by a consistent change in the PPR or CV ( $p=0.8125$ and 0.2188 , respectively), suggesting that postsynaptic mechanisms underlie the potentiation in both age groups. In contrast, the pairing-induced depression of EPSC size in younger birds $(<75 \mathrm{~d}$ old) was accompanied by an increase in the PPR from $0.8 \pm 0.17$ to $1.15 \pm 0.48$ ( $p=0.0156)$, suggesting a reduction in presynaptic transmitter release. Thus, LTP is inducible in area X of both adult and juvenile zebra finches but not observed in birds younger than $40 \mathrm{~d}$ old. In addition, the same form of LTP is present at the glutamatergic synapses in the medial striatum in adult female Bengalese finches ( $n=2$; data not shown), suggesting that this form of synaptic plasticity may be a common property in the basal ganglia of adult or late-juvenile songbirds.

Although LTP can be induced in cells obtained from both sexes and across a wide range of age, we were intrigued by its 

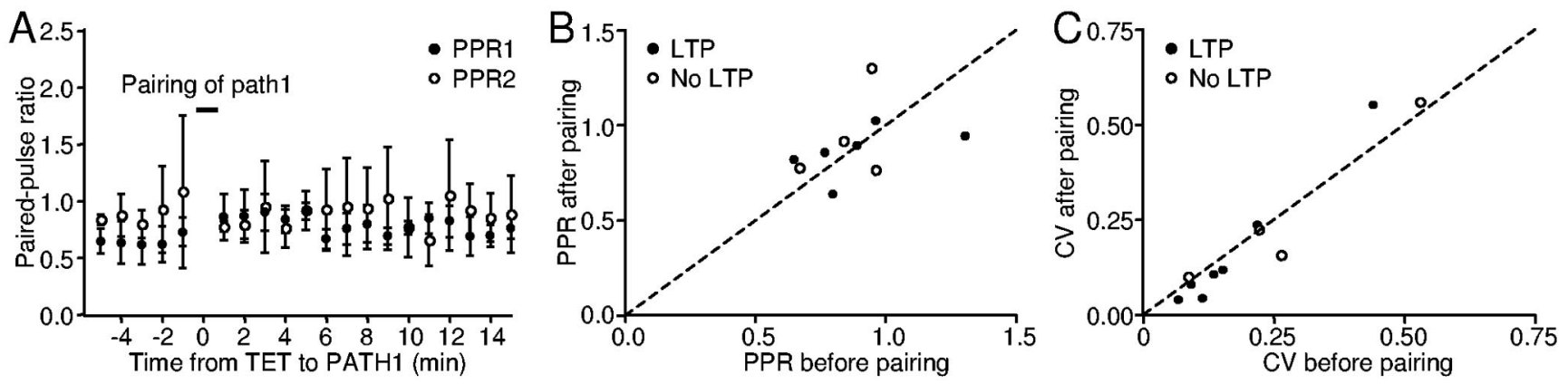

Figure 5. Pairing did not consistently change the PPR or CV of EPSC size. A, Time course of PPRs for the two pathways in the experiment shown in Figure $3 A$. There was no change in the PPR in either pathway. $B$, Summary of PPRs plotted before versus after pairing. Filled circles indicate data points taken from pathways potentiated after pairing; open circles, data points taken from pathways unchanged after pairing. The dashed line has a slope of 1. C, The CV in EPSC size was not changed after pairing. Note that in both $B$ and C, data points scatter on both sides of the dashed lines.

variability. A priori, such variability could result from inconsistent stimulation intensity during pairing or it could reflect heterogeneity in the spiny neurons. We compared the responses of cells during pairing, particularly the minimum, average, and maximum current deflections during the first 30 stimuli in the tetanus. We failed to observe a relationship between any parameter and the amount of potentiation (linear regression test, $r^{2}<$ 0.05 and $p>0.5$ for all). Visual inspection of the complete time courses of the pairing response also revealed no division between those that preceded LTP and the others. Thus, the variability in LTP induction cannot be explained easily by the response variation during pairing. We next tested whether the variability reflects multiple types of spiny
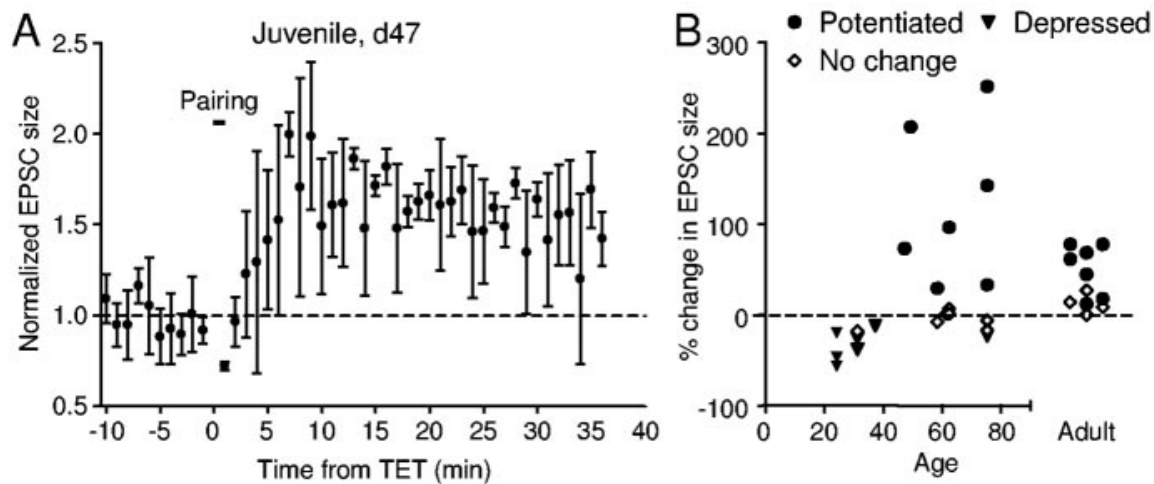

Figure 6. Pairing-induced LTP is also present in area $X$ of older juvenile zebra finches but is not observed in birds younger than $40 \mathrm{~d}$ old. $A$, Example from a spiny neuron in area $X$ of a zebra finch $47 \mathrm{~d}$ after hatching. $B$, Pairing can induce LTP in spiny neurons from zebra finches of age $47 \mathrm{~d}$ old to adulthood. Filled circles indicate experiments in which pairing induced significant potentiation; filled triangles, experiments in which pairing induced significant depression; open diamonds, experiments in which pairing had no effect on EPSC size or EPSP slope.

neurons. Although we did not observe any

relationship between the amount of potentiation and initial membrane potential, ramp index or input resistance (linear regression test, $r^{2}<0.05$ and $p>0.3$ for all), it remains to be investigated whether the variability in LTP induction correlates with other cellular properties (e.g., DA receptor distribution).

\section{Discussion}

We have provided evidence of LTP in a songbird brain nucleus required for normal song learning. Pairing of $100 \mathrm{~Hz}$ tetanic presynaptic stimulation and postsynaptic depolarization induces LTP at the glutamatergic synapses in spiny neurons of area X. This LTP occurs in both adult and older juvenile zebra finches but not in birds younger than $40 \mathrm{~d}$ of age. It requires presynaptic activity and postsynaptic depolarization and, thus, exhibits the properties characteristic of Hebbian learning. Furthermore, the LTP induction requires activation of NMDA and D1-like, but not D2-like, DA receptors.

\section{Functional relevance}

Our current knowledge of song-system physiology suggests that this form of LTP could be functional in vivo. Our data indicate that LTP can be induced by pairing presynaptic activity as low as $20 \mathrm{~Hz}$ and suprathreshold postsynaptic depolarization, or by pairing $100 \mathrm{~Hz}$ presynaptic activity with a postsynaptic depolarization to above $-40 \mathrm{mV}$, requirements that could easily be met in vivo. Spiny neurons in area $\mathrm{X}$ receive glutamatergic inputs from LMAN and HVC, in which projection neurons can produce action potentials at a rate of $100 \mathrm{~Hz}$. In LMAN projection neurons, $100 \mathrm{~Hz}$ bursts of action potentials were observed with depolarizing current injections in vitro (Livingston and Mooney, 1997; Boettiger and Doupe, 1998) and in vivo (Rosen and Mooney, 2000), as well as during song playback in anesthetized zebra finches (Hessler and Doupe, 1999). High-frequency ( $>100$ $\mathrm{Hz}$ ) bursts are also produced by area X-projecting HVC neurons in anesthetized zebra finches (Mooney, 2000). In addition to providing necessary presynaptic activation, this high-frequency activity may contribute to strong postsynaptic depolarization. Another source of prolonged postsynaptic depolarization could be the synaptically driven "up" states, as described in mammalian striatum and avian corticostriatal-like neurons in vivo (Wilson and Groves, 1981; Wilson and Kawaguchi, 1996; Reiner et al., 2001). A combination of the three necessary components (i.e., presynaptic activity, postsynaptic depolarization, and activation of DA receptors) can enable LTP induction at the glutamatergic synapses in area $\mathrm{X}$ in vivo.

The likelihood of LTP induction shows an increasing trend: $0 / 7$, $7 / 15$, and 7/11 in young, juvenile, and adult birds, respectively. This trend parallels the developmental increase in the density of dopaminergic innervation in area $\mathrm{X}$ relative to the surrounding medial striatum (Soha et al., 1996; Harding et al., 1998), consistent with the D1-like DA receptor dependence of LTP induction. Thus, although LTP is present in both juvenile and adult birds, its properties may be modulated in part by developmental changes in the dopaminergic innervation. It also seems very likely that LTP properties may be 
modulated at a finer time scale by different activity patterns of the dopaminergic neurons.

The developmental regulation of LTP induction imposes constraints on its possible functional roles. LTP is inducible in adult and juvenile birds, suggesting that it may contribute to song degradation in adult birds, induced by manipulations of auditory feedback or sectioning of tracheosyringeal nerves (Woolley and Rubel, 1997; Leonardo and Konishi, 1999; Williams and Mehta, 1999; Lombardino and Nottebohm, 2000; Brainard and Doupe, 2001), and to sensorimotor learning in juvenile birds. Although our inability to induce LTP in younger birds does not necessarily exclude its presence, the difficulty suggests that this form of plasticity may not play a primary role during sensory learning. Interestingly, the only known forms of plasticity in LMAN are restricted to the time of sensory learning (Boettiger and Doupe, 2001 ), inducible in birds of $\sim 20 \mathrm{~d}$ old but not so in birds of $60 \mathrm{~d}$ old. It remains unknown when the synaptic plasticity in LMAN disappears in relation to the sensorimotor learning period. Nonetheless, we can speculate that multiple forms of synaptic plasticity in different brain regions may play distinct roles in different phases during song learning.

The DA modulation is especially interesting in light of the observations that DA signals a prediction error of reward in mammals (Schultz, 2002). Conceivably, DAergic inputs from VTA could serve as a reinforcement signal related to the quality of the bird's own song, such as similarity to the memorized tutor song and song stereotypy (Doya and Sejnowski, 1995). Such a reinforcement signal could then guide sensorimotor learning in juvenile birds. Omission of this reinforcement signal, because of mismatch between song output and auditory feedback, could lead to a lack of proper potentiation, thereby providing the widely hypothesized error signal mediating song degradation in adult birds after altered auditory feedback or tracheosyringeal nerve section.

\section{Possible mechanisms}

We have found that the induction of LTP requires activation of presynaptic terminals and postsynaptic depolarization, similar to the classic hippocampal LTP observed at the CA3-CA1 synapse (Nicoll et al., 1988). Also, both types of LTP require activation of NMDA receptors and modulation of the intracellular $\mathrm{Ca}^{2+}$ level. In experiments using $\mathrm{Cs}^{+}$-based internal solution with the sodium channel blocker QX-314, the current response during pairing might serve as a crude estimate of the amount of calcium entry. Because the current response during pairing was not obviously correlated with the amount of potentiation, the total amount of calcium entry may not be the only factor. The source of calcium entry could be critical to LTP induction as well. There are two major sources of calcium entry: through NMDA receptors and voltage-gated calcium channels. Activation of voltagegated calcium channels alone, as in the experiments with postsynaptic depolarization alone or pairing in the presence of APV, is not sufficient to induce LTP. Thus, calcium entry through NMDA receptors is critical for LTP induction, similar to that for hippocampal synapses (Perkel et al., 1993).

The requirement for activation of D1-like DA receptors is intriguing. With our experimental paradigm, there are two possible sources of DA. DA could be released tonically such that there is a baseline level of DA in the slice. Alternatively, because both area $\mathrm{X}$ and the medial striatum are densely innervated by DAergic terminals, tetanic stimulation in these regions could evoke phasic release of DA in addition to glutamate. It will be important to examine whether such synchrony between phasic DA release and glutamate release is necessary for LTP induction.
The mechanisms downstream from D1-like DA receptor activation in this system await future investigation. D1-like DA receptors are expressed in the postsynaptic spiny neurons in area X (Ding and Perkel, 2002) and are linked with a G-protein complex that stimulates adenylyl cyclase (Memo et al., 1986; Ding et al., 2003). Conceivably, activation of adenylyl cyclase in the postsynaptic terminals may facilitate the induction of LTP or contribute to LTP expression. In addition, activation of D1-like DA receptors enhances L-type $\mathrm{Ca}^{2+}$ channels in medium spiny projection neurons in mammalian striatum (Hernandez-Lopez et al., 1997). A similar mechanism in spiny neurons of area X could also increase calcium entry and facilitate LTP induction. Because the PPR and CV of EPSCs were not altered after pairing, the potentiation may reflect purely postsynaptic changes.

\section{Comparison to avian LTP and mammalian corticostriatal LTP}

Compared with synaptic plasticity at glutamatergic synapses in other regions of the avian brain, LTP in area X shows similar NMDA receptor dependence to the LTP observed at the LMAN collaterals (Boettiger and Doupe, 2001) but not the LTP in the chick hippocampus (Wieraszko and Ball, 1993; Margrie et al., 1998). Interestingly, the NMDA receptor dependence is also shared by LTP induction at the mammalian corticostriatal synapses (Calabresi et al., 1992; Pennartz et al., 1993; Kombian and Malenka, 1994), further supporting the similarities between the avian and mammalian basal ganglia (Lewis et al., 1981; Vates and Nottebohm, 1995; Bottjer and Johnson, 1997; Reiner et al., 1998; Luo et al., 2001; Farries, 2002; Farries and Perkel, 2002). The dependence of DA and particularly D1-like DA receptor activation is also shared by the pairing-induced LTP in both area X and the mammalian dorsal striatum (Wickens et al., 1996; Centonze et al., 1999; Calabresi et al., 2000; Kerr and Wickens, 2001) but not in the nucleus accumbens (Pennartz et al., 1993). In area X, the D2-like DA receptor antagonist sulpiride had no effect on LTP induction. A similar lack of effect of sulpiride has been reported in mammalian striatum by one group (Kerr and Wickens, 2001), although other studies have shown an enhancement of LTP in the presence of sulpiride or in mutant mice lacking D2-like DA receptors (Calabresi et al., 1997). A recent study also reported activitydependent synaptic plasticity in the medial striatum of quail chicks (Matsushima et al., 2001). Although a D1-like DA receptor dependence was also reported, additional comparison was hindered by the possibility that different cell types were recorded and by the lack of knowledge of any involvement of NMDA receptors.

The pairing-induced long-term depression (LTD) of EPSC size in juvenile birds requires more detailed characterization. The increase in the PPR suggests presynaptically mediated depression, different from the mechanisms underlying LTP induction. It remains to be tested whether such depression results from endocannabinoid-mediated presynaptic depression, as reported for high-frequency tetanus-induced LTD at the mammalian corticostriatal synapses (Gerdeman et al., 2002). It will also be interesting to test whether LTP and LTD in area X are further modulated, for example, by activation of metabotrophic glutamate receptors, the nitric oxide pathway, or acetylcholine receptors, etc.

In conclusion, we have found evidence of DA and activitydependent synaptic plasticity in the avian basal ganglia. This form of synaptic plasticity may contribute to sensorimotor learning in juvenile songbirds and song maintenance in adults. Our work provides several molecular targets that may be susceptible to manipulation to test directly their involvement in normal song learning and maintenance. 


\section{References}

Boettiger CA, Doupe AJ (1998) Intrinsic and thalamic excitatory inputs onto songbird LMAN neurons differ in their pharmacological and temporal properties. J Neurophysiol 79:2615-2628.

Boettiger CA, Doupe AJ (2001) Developmentally restricted synaptic plasticity in a songbird nucleus required for song learning. Neuron 31:809-818.

Bottjer SW, Johnson F (1997) Circuits, hormones, and learning: vocal behavior in songbirds. J Neurobiol 33:602-618.

Bottjer SW, Miesner EA, Arnold AP (1984) Forebrain lesions disrupt development but not maintenance of song in passerine birds. Science 224:901-903.

Brainard MS, Doupe AJ (2000a) Interruption of a basal ganglia-forebrain circuit prevents plasticity of learned vocalizations. Nature 404:762-766.

Brainard MS, Doupe AJ (2000b) Auditory feedback in learning and maintenance of vocal behaviour. Nat Rev Neurosci 1:31-40.

Brainard MS, Doupe AJ (2001) Postlearning consolidation of birdsong: stabilizing effects of age and anterior forebrain lesions. J Neurosci 21:2501-2517.

Calabresi P, Pisani A, Mercuri NB, Bernardi G (1992) Long-term potentiation in the striatum is unmasked by removing the voltage-dependent magnesium block of NMDA receptor channels. Eur J Neurosci 4:929-935.

Calabresi P, Saiardi A, Pisani A, Baik JH, Centonze D, Mercuri NB, Bernardi G, Borrelli E (1997) Abnormal synaptic plasticity in the striatum of mice lacking dopamine D2 receptors. J Neurosci 17:4536-4544.

Calabresi P, Gubellini P, Centonze D, Picconi B, Bernardi G, Chergui K, Svenningsson P, Fienberg AA, Greengard P (2000) Dopamine and cAMP-regulated phosphoprotein $32 \mathrm{kDa}$ controls both striatal long-term depression and long-term potentiation, opposing forms of synaptic plasticity. J Neurosci 20:8443-8451.

Centonze D, Gubellini P, Picconi B, Calabresi P, Giacomini P, Bernardi G (1999) Unilateral dopamine denervation blocks corticostriatal LTP. J Neurophysiol 82:3575-3579.

Collingridge GL, Kehl SJ, McLennan H (1983) Excitatory amino acids in synaptic transmission in the Schaffer collateral-commissural pathway of the rat hippocampus. J Physiol (Lond) 334:33-46.

del Castillo J, Katz B (1954) Quantal components of the end-plate potential. J Physiol (Lond) 124:560-573.

Ding L, Perkel DJ (2002) Dopamine modulates excitability of spiny neurons in the avian basal ganglia. J Neurosci 22:5210-5218.

Ding L, Perkel DJ, Farries MA (2003) Presynaptic depression of glutamatergic synaptic transmission by D1-like dopamine receptor activation in the avian basal ganglia. J Neurosci 23:6086-6095.

Doya K, SejnowskiTJ (1995) A novel reinforcement model of birdsong vocalization learning. In: Advances in neural information processing systems 7 (Tesauro G, Touretzky DS, Leen TK, eds), pp 101-108. Cambridge, MA: MIT.

Farries MA (2002) Organization and electrophysiological properties of an avian basal ganglia structure essential for song learning. $\mathrm{PhD}$ thesis, University of Pennsylvania.

Farries MA, Perkel DJ (2002) A telencephalic nucleus essential for song learning contains neurons with physiological characteristics of both striatum and globus pallidus. J Neurosci 22:3776-3787.

Gerdeman GL, Ronesi J, Lovinger DM (2002) Postsynaptic endocannabinoid release is critical to long-term depression in the striatum. Nat Neurosci 5:446-451.

Harding CF, Barclay SR, Waterman SA (1998) Changes in catecholamine levels and turnover rates in hypothalamic, vocal control, and auditory nuclei in male zebra finches during development. J Neurobiol 34:329-346.

Hernandez-Lopez S, Bargas J, Surmeier DJ, Reyes A, Galarraga E (1997) D1 receptor activation enhances evoked discharge in neostriatal medium spiny neurons by modulating an L-type $\mathrm{Ca}^{2+}$ conductance. J Neurosci 17:3334-3342.

Hessler NA, Doupe AJ (1999) Singing-related neural activity in a dorsal forebrain-basal ganglia circuit of adult zebra finches. J Neurosci 19:10461-10481.

Immelmann K (1969) Song development in the zebra finch and other estrildid finches. In: Bird vocalizations (Hinde RA, ed). London: Cambridge UP.

Kerr JND, Wickens JR (2001) Dopamine D-1/D-5 receptor activation is required for long-term potentiation in the rat neostriatum in vitro. J Neurophysiol 85:117-124.

Kombian SB, Malenka RC (1994) Simultaneous LTP of non-NMDA- and LTD of NMDA-receptor-mediated responses in the nucleus accumbens. Nature 368:242-246.

Leonardo A, Konishi M (1999) Decrystallization of adult birdsong by perturbation of auditory feedback. Nature 399:466-470.

Lewis JW, Ryan SM, Arnold AP, Butcher LL (1981) Evidence for a catecholaminergic projection to area X in the zebra finch. J Comp Neurol 196:347-354.

Livingston FS, Mooney R (1997) Development of intrinsic and synaptic properties in a forebrain nucleus essential to avian song learning. J Neurosci 17:8997-9009.

Lombardino AJ, Nottebohm F (2000) Age at deafening affects the stability of learned song in adult male zebra finches. J Neurosci 20:5054-5064.

Luo M, Ding L, Perkel DJ (2001) An avian basal ganglia pathway essential for vocal learning forms a closed topographic loop. J Neurosci 21:6836-6845.

Malinow R, Tsien RW (1990) Presynaptic enhancement shown by whole-cell recordings of long-term potentiation in hippocampal slices. Nature 346:177-180.

Manabe T, Wyllie DJ, Perkel DJ, Nicoll RA (1993) Modulation of synaptic transmission and long-term potentiation: effects on paired pulse facilitation and EPSC variance in the CA1 region of the hippocampus. J Neurophysiol 70:1451-1459.

Margrie TW, Rostas JA, Sah P (1998) Long-term potentiation of synaptic transmission in the avian hippocampus. J Neurosci 18:1207-1216.

Matsushima T, Izawa EI, Yanagihara S (2001) D1-receptor dependent synaptic potentiation in the basal ganglia of quail chicks. NeuroReport 12:2831-2837.

Memo M, Missale C, Carruba MO, Spano PF (1986) Pharmacology and biochemistry of dopamine receptors in the central nervous system and peripheral tissue. J Neural Transm Suppl 22:19-32.

Mooney R (2000) Different subthreshold mechanisms underlie song selectivity in identified HVc neurons of the zebra finch. J Neurosci 20:5420-5436.

Nicoll RA, Kauer JA, Malenka RC (1988) The current excitement in longterm potentiation. Neuron 1:97-103.

Nordeen KW, Nordeen EJ (1992) Auditory feedback is necessary for the maintenance of stereotyped song in zebra finches. Beh Neural Biol 57:58-66.

Nottebohm F, Stokes TM, Leonard CM (1976) Central control of song in the canary, Serinus canarius. J Comp Neurol 165:457-486.

Pennartz CMA, Ameerun RF, Groenewegen HJ, Dasilva FHL (1993) Synaptic plasticity in an in vitro slice preparation of the rat nucleus accumbens Eur J Neurosci 5:107-117.

Perkel DJ, Petrozzino JJ, Nicoll RA, Connor JA (1993) The role of $\mathrm{Ca}^{2+}$ entry via synaptically activated NMDA receptors in the induction of longterm potentiation. Neuron 11:817-823.

Reiner A, Medina L, Veenman CL (1998) Structural and functional evolution of the basal ganglia in vertebrates. Brain Res Rev 28:235-285.

Reiner A, Stern EA, Wilson CJ (2001) Physiology and morphology of intratelencephalically projecting corticostriatal-type neurons in pigeons as revealed by intracellular recording and cell filling. Brain Beh Evol 58:101-114.

Reiner A, Perkel DJ, Bruce LL, Butler AB, Csillag A, Kuenzel W, Medina L, Paxinos G, Shimizu T, Striedter G, Wild M, Ball GF, Durand S, Gunturkun O, Lee D, Mello CV, Powers A, White SA, Hough G, Kubikova L, Smulders TV, Wada K, Dugas-Ford J, Husband S, Yamamoto K, Yu J, Siang C, Jarvis ED (2004) Revised nomenclature for avian telencephalon and some related brainstem nuclei. J Comp Neurol, in press.

Rosen MJ, Mooney R (2000) Intrinsic and extrinsic contributions to auditory selectivity in a song nucleus critical for vocal plasticity. J Neurosci 20:5437-5448.

Scharff C, Nottebohm F (1991) A comparative study of the behavioral deficits following lesions of various parts of the zebra finch song system: implications for vocal learning. J Neurosci 11:2896-2913.

Schultz W (2002) Getting formal with dopamine and reward. Neuron 36:241-263. Soha JA, Shimizu T, Doupe AJ (1996) Development of the catecholaminergic innervation of the song system of the male zebra finch. J Neurobiol 29:473-489.

Sohrabji F, Nordeen EJ, Nordeen KW (1990) Selective impairment of song learning following lesions of a forebrain nucleus in the juvenile zebra finch. Behav Neural Biol 53:51-63.

Vates GE, Nottebohm F (1995) Feedback circuitry within a song-learning pathway. Proc Natl Acad Sci USA 92:5139-5143.

Wickens JR, Begg AJ, Arbuthnott GW (1996) Dopamine reverses the depression of rat corticostriatal synapses which normally follows highfrequency stimulation of cortex in vitro. Neuroscience 70:1-5.

Wieraszko A, Ball GF (1993) Long-term potentiation in the avian hippocampus does not require activation of the $N$-methyl-D-aspartate (NMDA) receptor. Synapse 13:173-178.

Williams H, Mehta N (1999) Changes in adult zebra finch song require a forebrain nucleus that is not necessary for song production. J Neurobiol 39:14-28.

Wilson CJ, Groves PM (1981) Spontaneous firing patterns of identified spiny neurons in the rat neostriatum. Brain Res 220:67-80.

Wilson CJ, Kawaguchi Y (1996) The origins of two-state spontaneous membrane potential fluctuations of neostriatal spiny neurons. J Neurosci 16:2397-2410.

Woolley SMN, Rubel EW (1997) Bengalese finches Lonchura striata domestica depend upon auditory feedback for the maintenance of adult song. J Neurosci 17:6380-6390. 